\title{
Studying and Learning during Crisis Situations
}

\author{
Maria Vittoria Isidori
}

Department of Human Sciences, University of L'Aquila, Aquila, Italy

\begin{abstract}
Catastrophes (floods, earthquakes, industrial accidents) require exceptional logistic, health, psychological, educational and social intervention in the areas they occur. In this paper, we present the results of a study carried out on University students in post-emergency conditions in the city of L'Aquila, Italy, two years after the devastating 2009 earthquake, in order to individuate the consequences that this catastrophic event had on student motivation and academic performance. This paper aims at outlining aspects of learning and studying in critical situations and defining a teaching intervention model to be adopted under such conditions.
\end{abstract}

Keywords Catastrophe, Emergency, Stress, Study, Learning

\section{Introduction}

Studying is a complex activity involving an intentional application of the mind to the acquisition and memorising of knowledge and information needed to carry out a task or test. It may be associated with the perception of a threat to one's self- esteem, safety and way of life.

Repeated failure can lead to conditions of learned helplessness in students, while success and progress in a scholastic setting can stimulate students' confidence in their abilities and develop a sense of empowerment allowing them to acquire coping strategies that can help to limit the debilitating effects of stress $[1 ; 2 ; 3]$.

Learning during emergency and post-emergency situations is conditioned by stress and trauma. Subjects being taught are facing high levels of stress and in $7-14 \%$ of cases suffering from post traumatic stress disorder (PTSD). If these conditions are not taken into consideration within the teaching strategies adopted, various types of learning disorders may arise $[4 ; 5 ; 6 ; 7 ; 8]$.

This theory has been verified in various studies conducted on students who experienced the 2009 earthquake in the city of L'Aquila, Italy[9].

The results obtained are presented in this article, however, as we shall see, they cannot be generalised.

It is, in any case, important to ask: how can teaching and education allow individuals and groups to regain hope for the future after having gone through a catastrophic event? Can learning represent a means of re-elaborating individual and collective trauma? How can we develop teaching strategies able to enhance the learning process under

* Corresponding author:

mairavittoriaisidori@virgilio.it (Maria Vittoria Isidori)

Published online at http://journal.sapub.org/edu

Copyright (C) year Scientific \& Academic Publishing. All Rights Reserved traumatic and post-traumatic situations?[10].

\subsection{The context of a study on motivation carried out on students at the University of L'Aquila}

\subsubsection{Emergency and Post- emergency}

In the aftermath of the devastating earthquake that hit the city of L'Aquila, capital of the Abruzzi Region, leaving 309 dead, thousands injured and 52,000 homeless, a group of pedagogists at the University of L'Aquila conducted research on pedagogy and teaching during emergency and post-emergency situations in order to create a general plan to cope with such situations and experiment it at the same time.

\subsubsection{Effects of Earthquake on Educational Institutions: the case of the University of L'Aquila.}

Before the devastating 2009 earthquake, the University of L'Aquila, with approximately 20.000 students enrolled, was a vital centre for the city's social, cultural and economic livelihood (70,000 inhabitants) making it an important "university town". The earthquake took a devastating toll on the University: among the 309 victims, 55 were university students, $70 \%$ of university buildings and facilities were destroyed thus paralysing teaching, research and administration procedures and causing extensive student displacement due to lack of housing and consequent commuting difficulties. In spite of this, the University of L'Aquila managed to reactivate teaching, exam sessions, research and degree consignments immediately following the earthquake. However, to this day, research laboratories, libraries, canteens and student meeting points are still lacking.

\section{Research}




\subsection{Hypothesis}

We found it important to verify to what extent the 2009 earthquake and its aftermath effected student motivation, proficiency and academic performance. In this paper we shall mainly examine effects on motivation.

The students of the University of L'Aquila represent ideal subjects for this type of study because they include both subjects who were in the city at the moment of the earthquake and others who enrolled in the period following the devastating event.

In general we expected a marked difference between those who had experienced the earthquake and those who had only experienced the post- earthquake situation.

\subsection{Tools}

The questionnaire adopted for this study was rigidly structured and consisted in multiple choice questions aimed at assessing attitudes, orientation and motivation as well as obtaining an evaluation of life at the university and, in general, of living conditions in the city of L'Aquila.

The variables and question-types together with the possible answers allowed for a descriptive approach, above all regarding single variable analysis (frequency, mean, standard deviation) together with an explicative approach, which allowed us to survey the relationship between two variables through conditional mean analysis, variance analysis (ANOVA), chi-square calculations, Pearson's $r$ and Spearman's rank correlation coefficient $[11 ; 12 ; 13]$.

\subsection{Group Studied}

The questionnaire was submitted to a group of 220 subjects selected randomly among students outside the various student-affairs offices of the University Departments. The number of participating subjects fulfils criteria for sample range of $95 \%$.

The group studied was not homogeneous as the subjects belonged to different Departments and were of different ages and gender: $30.6 \%$ male, 69.4 female, while 25.3 was their average age. $27.8 \%$ of participating students lived in L'Aquila and were earthquake survivors. About half of the participating subjects were full-time students.

To verify our main hypothesis we followed the principle of comparing and contrasting two distinct groups:

Group 1: students in L'Aquila on the night of the April 6th 2009 earthquake (142 subjects);

Group 2: students who did not directly experience the earthquake ( 78 subjects).

The initial differences emerging between the two groups was that in group 2 the average age of subjects was higher and more of them had regular jobs in comparison with group 1; while in group 1 the participants attended lessons more frequently than subjects in group 2 .

In group 1 more of the subjects resided in the central area hit by the earthquake while in group 2 more participants lived outside the core earthquake area. Gender and grade point average were evenly distributed in the two subgroups.

\section{Results}

\subsection{Studying in the immediate aftermath}

142 students, $64.5 \%$ of the total number, experienced the earthquake. Six months following the devastating event, $67.7 \%$ was unable to study proficiently while $32.3 \%$ was able to carry out studies proficiently. The negative conditions hindering students from proficient studying were identified as: inability to concentrate due to state of mind (37.1\%), reasons linked to logistics $(28.4 \%)$, doubts as to where and how to continue their studies (17.2\%), lack of available information regarding course programmes, schedules etc. $(6 \%), 11.2 \%$ answered "other" indicating conditions linked to their state of mind.

Studying represented "other" in a moment of great distress. On one hand it offered students a way of escaping from the terrible situation they were living through $(24.2 \%)$, a way of envisioning a better future (19.7\%), a stable "fixed point" in contrast with the uncertainty caused by the catastrophic event (15.2\%) ; on the other hand some subjects had a negative impact with the act of studying as it represented an ulterior cause of anxiety and stress (18.9\%), or was considered something unimportant in comparison with the dramatic situation experienced (13.6\%).

Table 1. Significance attributed to studying

\begin{tabular}{ccc}
\hline & V.a. & $\%$ \\
\hline $\begin{array}{c}\text { 1 One of the few "reference points" remaining in the } \\
\text { midst of the uncertainty caused by the quake }\end{array}$ & 20 & 15,2 \\
2 A way of envisioning a better future & 26 & 19,7 \\
3 A way of employing my time and not thinking & 32 & 24,2 \\
$\quad \begin{array}{c}\text { about bad things } \\
\text { 4 An insignificant and unimportant activity in the midst } \\
\text { of the drama I'm experiencing }\end{array}$ & 18 & 13,6 \\
5 An ulterior cause of anxiety and stress & 25 & 18,9 \\
6 Other & 11 & 8,3 \\
\hline Total & 132 & 100,0 \\
\hline
\end{tabular}

We then proceeded to identify possible connections between studying and critical situations linked to the earthquake. Neither the subjects' immediate perception of the devastation caused by the earthquake nor the case of victims among family members or friends - potential causes of psychic trauma - indicated significant differences among students as regards difficulty in studying in the 6 month aftermath of the earthquake.

This leads us to consider that studying could actually be a "means" for individual resilience, especially in situations in which a catastrophic event eliminates tangible certainties and subjects therefore turn to intangible aspects of life. This data is confirmed two years after the earthquake as well.

\subsection{Student Motivation after the Catastrophe}

To assess the situation regarding motivation towards university studies affective variables (self-esteem, motivational orientation, significance attributed to studying and learning), proficiency (grade point average, failures etc.) 
we not only compared the two main groups but also carried out a comparison of the subjects within group 1 - subjects who experienced the earthquake - focusing on the effects of the catastrophe on their individual lives.

While no significant difference was revealed regarding proficiency between the two groups, we observed differences as regards the number of hours dedicated to studying in periods before exam sessions, together with motivational intensity. In group 1 , subjects dedicated an average of $6 \mathrm{hrs}$ and $50 \mathrm{~min}$., in comparison to $5 \mathrm{hrs}$ and 41 min. for group 2; the grade point average instead was the same for both groups (26/30 on exams).

Table 2. Group. Hours spent studying. Average marks

\begin{tabular}{cccc}
\hline Group & & Hours study & Average marks \\
\hline 1 & $\mathrm{M}$ & 6.50 & 26.28 \\
& $\mathrm{SD}$ & 2.791 & 3.099 \\
\hline 2 & $\mathrm{M}$ & 5.41 & 26.48 \\
& $\mathrm{SD}$ & 2.124 & 1.871 \\
\hline \multirow{2}{*}{ Total } & $\mathrm{M}$ & 6.17 & 26.35 \\
& $\mathrm{SD}$ & 2.651 & 2.730 \\
\hline
\end{tabular}

The total level of motivation was obtained by adding up the various scores (1-4) of 22 the motivational indicators used. Motivation - commitment and energy spent on a task prevailed in group 1-students who had directly experienced the earthquake[group $1(65,43 \pm 11,480)$; group $2(62,17 \pm$ $10,467)$. The same group also obtained higher scores in terms of consistency, concentration, interest in study materials.

Table 3. Relatives and friends among victims and motivational levels

\begin{tabular}{ccccc}
\hline \multicolumn{5}{c}{ Motivational Levels } \\
Victims & Low & Medium & High & Total \\
\hline Yes & 6 & 25 & 33 & 64 \\
& $9,4 \%$ & $39,1 \%$ & $51,6 \%$ & $100,0 \%$ \\
\hline No & 3 & 50 & 18 & 71 \\
& $4,2 \%$ & $70,4 \%$ & $25,4 \%$ & $100,0 \%$ \\
\hline \multirow{2}{*}{ Total } & 9 & 75 & 51 & 135 \\
& $6,7 \%$ & $55,6 \%$ & $37,8 \%$ & $100,0 \%$ \\
\hline
\end{tabular}

In group 1 we also looked at the relationship between student motivation and more serious traumatic experiences (death of a family member or friend during the earthquake) and found that students who had relatives or friends among the quake victims showed higher levels of motivation.

To identify motivational levels we used 8 indicators representing intrinsic and extrinsic factors able to characterise motivation. In this case as well students in group 1 obtained higher scores.

This study supports the idea that a catastrophic experience can enhance the need for what is intangible, leading individuals to not give up and work harder to fulfil their objectives in terms of cultural growth and future employment
Table 4. Group per motivational orientation

\begin{tabular}{cccc}
\hline Group & & Intrins & Estrins \\
\hline 1 & $\mathrm{M}$ & 12,60 & 8,91 \\
& $\mathrm{SD}$ & 2,224 & 2,328 \\
\hline 2 & $\mathrm{M}$ & 11,69 & 8,47 \\
& $\mathrm{SD}$ & 2,531 & 2,490 \\
\hline Total & $\mathrm{M}$ & 12,28 & 8,75 \\
& $\mathrm{SD}$ & 2,371 & 2,390 \\
\hline & $\mathrm{F}$ & 7,272 & 1,691 \\
& Sig. &, 008 &, 195 \\
\hline & & &
\end{tabular}

As regards emotional conditions linked to studying we used 17 different indicators. Tension, anxiety and irritability are factors that can generally apply to studying for exams. In particular, pre- exam anxiety, irritability and crying were more marked in group 1. A significant statistical difference can be seen between the two groups thus underlining that two years following the devastating quake the consequences of the trauma experienced were evident, even those directly linked to studying.

\section{Conclusions}

This study revealed that motivation towards learning, defined mainly as time and commitment dedicated to a task, is greater in the group of students who experienced the 2009 earthquake. Two years following the quake we can assume that student dedication to their studies was twofold: on one hand studying represented a way towards a better future (studying could make up for the damage and loss) on the other hand, through their studies students expressed their will to survive and not be overcome by the adversity the earthquake had caused in their lives.

Intervention on an educational level during emergency situations must focus on helping young people in:

- overcoming learned helplessness which afflicts subjects facing adverse conditions;

- developing control and coping strategies

- carrying out recognition of the event experienced focusing on three emotional-cognitive dimensions: causal attribution, assessment strategies and prefiguring a better future $[14 ; 15 ; 16 ; 17]$.

In general, from the educational point of view, but not limited to direct actions to the community, it is important to promote the development of a culture of prevention of risk situations including those related to environmental disasters. This is because the critical situations produce serious effects on social and existential conditions of individuals. Taking into account the social responsibility of educational functions and interpreting the motivation to study as a real life skills can say that an intervention must focus on helping young people acquire strategies that will allow them to develop skills for social emotional, cognitive and physical resilience. These conditions are imperative in constructing this type of pedagogic-educational model[18;19;20;21]. 


\section{REFERENCES}

[1] Mak W.W.S., Ng I.S.W., Wong C.C.Y., "Resilience: enhancing well-being through the positive cognitive triad", Journal of counseling psychology, vol.58, no.4, pp.610-617, 2011.

[2] Ning H., Downing K., "Influence of student learning experience on academic performance: the mediator and moderator effects of self-regulation and motivation", British educational research journal, vol.38, no.2, pp.219-237, 2012.

[3] Abutinch A. M, "Exploring the relationship between organizational learning and career resilience among faculty members at qatar university", International Journal of Educational Management, vol.25, no.6, pp.635-650, 2011.

[4] Anderson J.R., “Acquisition of cognitive skill, Psychological Review”, vol.89, pp.369-406, 1982.

[5] Castelli C., Sbattella, F., "Psicologia dei disastri: interventi relazionali in contesti d'emergenza", Roma, Carocci 2003.

[6] American Psychiatric Association. Manuale Diagnostico e Statistico dei Disturbi Mentali, Quarta Edizione Rivista (Trad. it.) 2001. Milano, Masson 2000.

[7] Rossi A., Maggio R., Riccardi I., Allegrini F., Stratta P., “A quantitative analysis of antidepressant and antipsychotic prescriptions following an earthquake", Italy Journal of Traumatic Stress, vol.24, no.1, pp.129-132, 2011.

[8] Turley M.R., Obrzut J.E., "Neuropsychological effects of posttraumatic stress disorder in children and adolescents", Canadian Journal of School Psychology, no.2, 2012.

[9] Casacchia M., Rossi, A., Relazione di presentazione del progetto "Benessere psicologico", finalizzato allo studio dei disagi legati al post sisma. Università degli Studi dell'Aquila, 2011.

[10] Preston J., .Avery B., Chakrabarty N., Edmonds C. "Emergency preparedness as public pedagogy: the absent-presence of race in "preparing for emergencies", International Journal of Lifelong Education, vol. 30, no.6, pp.749-762, 2011.

[11] Laeng M., "Pedagogia sperimentale", Firenze, La Nuova Italia, 1992.

[12] Lombardo E., "I dati statistici in pedagogia. Esplorazione e analisi”, Firenze, La Nuova Italia, 1993.

[13] Isidori M.V.,Vaccarelli A., "Formare e apprendere in situazioni di emergenza e di post emergenza", Roma, Armando, 2012.

[14] Hartley M.T., "Environmental education, resilience and learning: reflection and moving forward", Journal of American College Health, vol. 59, no.7, pp.596-604, 2011.

[15] Lazarus R.S., "Coping theory and research: Past, present and future”, Psychosomatic Medicine, vol.55, pp.237-247, 1993.

[16] Pilar A., Gonzalo, R., "Protective environments and quality education in humanitarian contexts", International Journal of Educational Development, vol.29, no.1, pp. 3-16, 2009.

[17] Larcan R., Cuzzocrea F., "Emergencies and disasters: Children's vulnerability and psychosocial resilience", Environmental Semeiotics, vol. 3, no 4, pp. 42-56, 2010.

[18] Contini M., "La comunicazione intersoggettiva tra solitudini e globalizzazione”. Firenze, La Nuova Italia. 2002.

[19] Mantegazza R., "Pedagogia della resistenza. Tracce utopiche per educare a resistere", Torino, Città Aperta, 2003.

[20] Action Guide for Emergency Management at Istitutions of Higher Education. U.S.Department of Education Office of Safe and Drug-Free Schools , 2010.

[21] Report to the Congressional Requesters, "Urricanes Katrina and Rita Temporary Emergency impact Aid Provided education Support for Displaced Students". United States Government Accontability Office. GAO-11-839, 